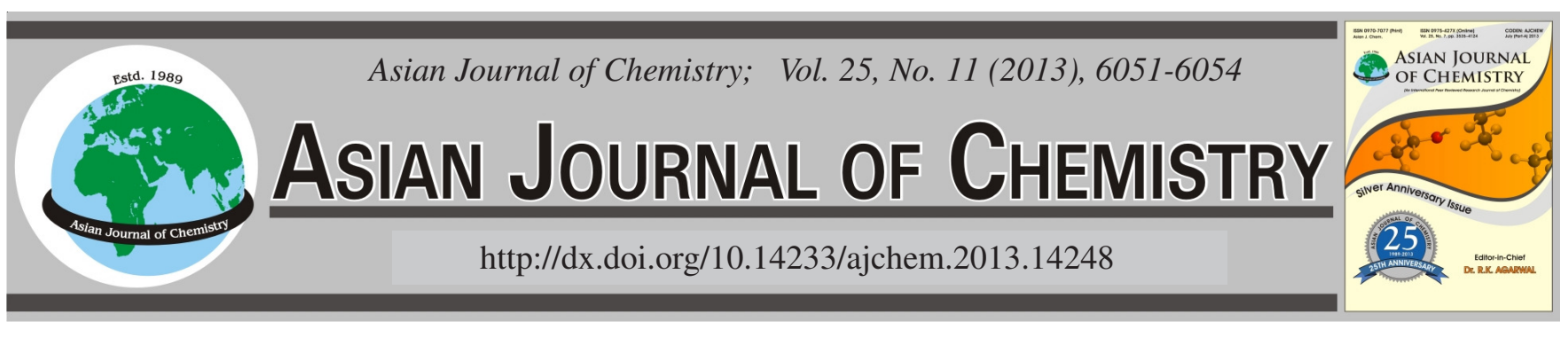

\title{
Kinetic Fluorescence Determination of Formaldehyde in Water Samples
}

\author{
Q. ZHAO and L.H. CHEN*
}

College of Chemistry and Materials Science, Huaibei Normal University, Huaibei 235000, P.R. China

*Corresponding author: E-mail: lanhuachen@126.com

(Received: 30 June 2012;

Accepted: 26 April 2013)

AJC-13399

A novel kinetic fluorescence analytical method for determination formaldehyde in environmental water samples has been developed. It was based on the catalytic effect of formaldehyde for the oxidation of thionine by potassium bromate, leading to the colour fading and fluorescence weakening in hydrochloric acid medium. Under the optimized conditions, the limit of determination, based on three times of the standard deviation of the reagent blank, was $5.8 \mu \mathrm{g} / \mathrm{L}$. The calibration graph of linear was in the range of 10.0-300 $\mu \mathrm{g} / \mathrm{L}$. The method was applied to the detection of formaldehyde in environmental river water and well water, the recovery of river water samples were in the range of 98.3-101.6\% and the recovery of well water samples were in the range of 97.6-102.8\%.

Key Words: Kinetic fluorescence, Formaldehyde, Thionine, Potassium bromate.

\section{INTRODUCTION}

Formaldehyde is the most common pollutant in the environment. It is widely exist in water and air environments as one of environmental pollutants. It is known to cytotoxic, mutagenic and carcinogenic for human health and to be irritating the respiratory tract, nose, mouth, throat, etc. ${ }^{1,2}$. Formaldehyde was increased to the first level carcinogen from the original probable carcinogen by International Agency for Research on Cancer (IARC) in the annual report. At present, the main sources of pollution of formaldehyde in the environment are incomplete combustion of fossil fuels, vehicle exhaust, construction and decoration materials, industrial waste water and waste gas and so on. Due to the influence of formaldehyde to nature and human beings, establishment a simple, sensitive and selective method, determination of formaldehyde in the environmental water samples, is urgently required.

Many methods have been reported for the determination of formaldehyde. All of these, spectrophotometric method has been widely applied for the detection of formaldehyde ${ }^{3,4}$. The traditional spectrophotometry is lower sensitivity, therefore, the use of the spectrophotometric methods in conjunction with other methods are used recently. For example, Ensafi and Honarmand ${ }^{5}$ developed, a flow injection method, for the determination of formaldehyde with spectrophotometric detection and the calibration graph was linear in the range of 5.0-2800 $\mu \mathrm{g} / \mathrm{L}$. This method was applied to the determination of formaldehyde in river water, shampoo and melamine-formaldehyde resin. Li et $a l .{ }^{6}$ also provided a method for the determination of formaldehyde in foodstuffs by using flow injection spectrophometry. Afkhami and Bagheri ${ }^{7}$ provided a method for the determination of formaldehyde, which was based on the use of modified alumina nanoparticles for its preconcentration and then detected by catalytic kinetic method. The detection limit is lower, but the method has narrower linear range and other disadvantages. Although spectrophotometric method in conjunction with other methods improves the sensitivity of determination, the cost of tests increase and the processes become more complex.

Chromatographic is preeminent among analytical separation methods. It offers rapid and high resolution separations of a very wide range of compounds. So, many researchers proposed new methods for the determination of formaldehyde by using $\mathrm{GC}^{8,9}$. For example, Kim and $\mathrm{Kim}^{10}$ reviewed the application of GC to the detection of various families of environmental formaldehyde. This article investigated the effects of the determination formaldehyde and obtained a satisfactory results. Other articles also reported for the determination of formaldehyde by using HPLC ${ }^{11,12}$. Liu et al $^{13}$ proposed a novel method for the determination of formaldehyde in shiitake mushroom by liquid-phase microextraction coupled with HPLC. In this study, using ionic liquid as extraction solvent and 2,4-dinitrophenylhydrazine as derivative agent, the provided procedure has detection limit $(5 \mu \mathrm{g} / \mathrm{L})$ of formaldehyde in extraction solution. However, most of the chromatographic methods for determination of formaldehyde require compound being analyzed should have sufficient volatility, expensive equipment and more time in further derivatization steps. 
In addition, the determinations of formaldehyde by polarography ${ }^{14,15}$ and chemiluminescence ${ }^{16,17}$ are also reported.

In recent years, the kinetic fluorescence method has the advantages of high sensitivity, good selectivity and simple operation. Many researchers ${ }^{18-21}$ have been the most frequently introduced to the determination of formaldehyde, such as $\mathrm{Li}$ et al. ${ }^{21}$ developed a kinetic fluorescence method for measurement of formaldehyde by using acetoacetanilide which was based on Hantzsch reaction at room temperature. This method was used to the determination of formaldehyde in environmental water samples. Liu and Chen ${ }^{22}$ proposed a new catalytic fluorescence to measure trace formaldehyde in food, the linear range of the determination for formaldehyde content was $0.016-0.14 \mathrm{mg} / \mathrm{L}$ and the detection limit was $8.6 \times 10^{-6} \mathrm{~g} / \mathrm{L}$. Fan et al $^{23}$ developed a method for the determination of formaldehyde in fabric based on its catalytic effect on the oxidation of rhodamine $6 \mathrm{G}$ with potassium bromate, which was little interference with common organic substances.

The aim of the present work is to develop a method, the low cost, highly sensitive and selective, for the determination of formaldehyde. The present method proposed the the kinetic fluorescence to the determination of formaldehyde in environmental water. The method was based on the formaldehyde has significantly catalytic effect on the oxidation of thionine by potassium bromate, leading to the fluorescence reduction in dilute hydrochloric acid medium. The intensity of thionine fluorescence and concentration of formaldehyde showed a good linearity in certain concentration range. Moreover, the preconcentration and determination steps of this research are rapid and no complex laboratory procedures required.

\section{EXPERIMENTAL}

F96 (Leng Guang Technology Co. Ltd., Shanghai) was used to optimize the experiment conditions. RF-5301 PC (Shimadzu, Japan) was used to scan the fluorescence spectra features of Thionine. The temperature of experiments was controlled by Super CS-501 thermostat (Chongqing Test Equipment Factory).

All reagents used were analytical grade and the double distiller water was used throughout the experiment. The 5 $\mathrm{mg} / \mathrm{L}$ standard stock solution of formaldehyde was prepared by dissolving $2.50 \mathrm{~mL}$ of $37.0 \%-40.0 \% \mathrm{HCHO}$ solution (Xuzhou Chemical Reagent Factory) to $1 \mathrm{~L}$ with double distilled water, using the iodometric method to determinate the accurate concentration and diluting to $5 \mathrm{mg} / \mathrm{L}$ working solution before used. The $1.0 \times 10^{-4} \mathrm{~mol} / \mathrm{L}$ solution of thionine (Shanghai Chemical Reagent Factory) was prepared by dissolving $0.2873 \mathrm{~g}$ in double distilled water to $100 \mathrm{~mL}$, diluting to $1.0 \times 10^{-4} \mathrm{~mol} / \mathrm{L}$ working solution. $0.8350 \mathrm{~g}$ potassium bromate $(0.02 \mathrm{M})$ dissolved in $250 \mathrm{~mL}$ with double distilled water, which obtained from Shanghai Reagent Factory. 0.01 $\mathrm{M}$ hydrochloric acid solution was prepared by appropriate dilution of concentrated hydrochloric acid.

$1.5 \mathrm{~mL}$ of $1.0 \times 10^{-4} \mathrm{M}$ thionine, $2.0 \mathrm{~mL}$ of $0.01 \mathrm{M} \mathrm{HCl}$, $1.2 \mathrm{~mL}$ of $0.02 \mathrm{M} \mathrm{KBrO}_{3}$ and an appropriate formaldehyde was added into $10 \mathrm{~mL}$ colourimetric tube in sequence. In the meantime, blank test was carried out. Then the two colourimetric tubes were diluted to scale line with double distilled water. Finally, after heating for $10 \mathrm{~min}$ at $100^{\circ} \mathrm{C}$, the solutions cooled to room temperature about $4 \mathrm{~min}$. The results of the experiment were determined through RF-5301 PC fluorescence spectrophotometer and obtained the fluorescence value of containing formaldehyde $(\mathrm{F})$ solution and blank reagent $\left(\mathrm{F}_{0}\right)$ solution. At last, calculate the $\Delta \mathrm{F}\left(\Delta \mathrm{F}=\mathrm{F}_{0}-\mathrm{F}\right)$ value of the corresponding containing formaldehyde.

\section{RESULTS AND DISCUSSION}

Fluorescence spectra: The thionine solutions of several different systems of excitation and emission spectra were scanned using RF-5301 PC fluorescence spectrophotometer. The maximum wavelength of the excitation and the emission were $594 \mathrm{~nm}$ and $621 \mathrm{~nm}$ (Fig. 1), respectively. Curve1-1' showed the fluorescence spectra of Thionine solution in $\mathrm{HCl}$ medium, however, the solution of the fluorescence intensity did not change when a certain amount of $\mathrm{HCHO}$ was added. The fluorescence intensity was weaken while $\mathrm{KBrO}_{3}$ was added (curve 2-2'), but the phenomenon was not obvious. Whereas HCHO existed in the oxidation system (curves 3-3'), the solution of fluorescence intensity clearly decreased, which indicated that $\mathrm{HCHO}$ had a notable catalysis for the oxidation reaction. Additionally, we also obtained a good relationship between the concentrate of $\mathrm{HCHO}$ and the value of $\Delta \mathrm{F}$.

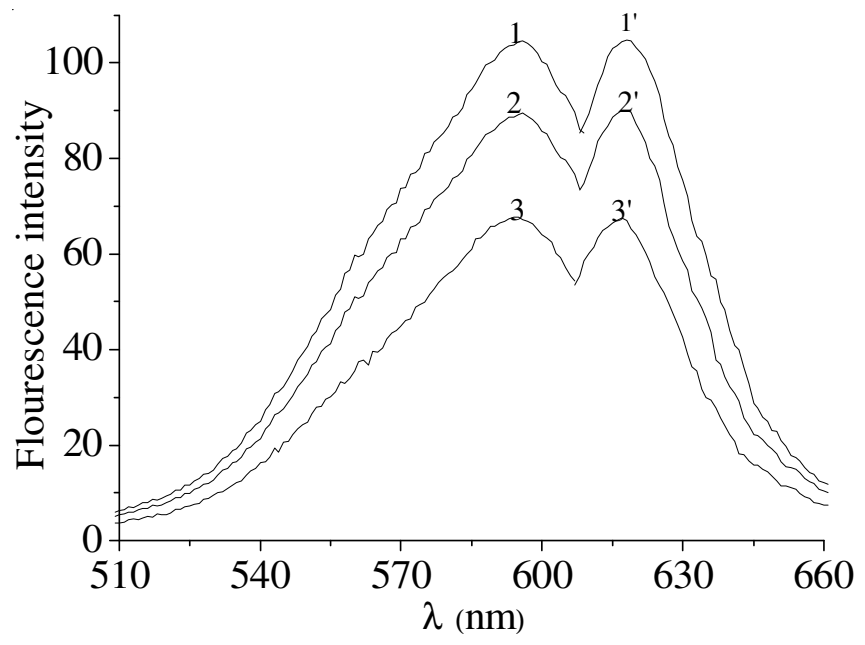

Fig. 1. Excitation and emission spectra

Effect of thionine: In order to improve the sensitivity and selectivity for determination of trace formaldehyde, we investigated the effect of thionine concentrates from $1.0 \times 10^{-5}$ $\mathrm{M}$ to $1.0 \times 10^{-3} \mathrm{M}$. The results indicate $\Delta \mathrm{F}$ was increasing with concentrations of Thionine from $1.0 \times 10^{-5} \mathrm{M}$ to $1.0 \times 10^{-4} \mathrm{M}$. When the concentration of thionine increased to $1.0 \times 10^{-4} \mathrm{M}$, $\Delta F$ reached a maximum value. Thionine concentration continued to increase, the value of $\Delta \mathrm{F}$ decreased. At the time, the optimize volume of thionine was also investigated and the results showed $1.5 \mathrm{~mL}$ thionine was the best volume. Then a $1.5 \mathrm{~mL} 1.0 \times 10^{-4} \mathrm{M}$ of thionine solution was used as optimal for at which the highest value of $\Delta \mathrm{F}$ was obtained.

Effect of $\mathbf{H C l}$ : The volumes of $0.01 \mathrm{M}$ of $\mathrm{HCl}$ were studied at $0.2-3.0 \mathrm{~mL}$. The $\Delta \mathrm{F}$ gradually increased with concentrations of $\mathrm{HCl}$ from $0.2 \mathrm{~mL}$ to $2.0 \mathrm{~mL}$. When the volume of $\mathrm{HCl}$ was up to $2.0 \mathrm{~mL}, \Delta \mathrm{F}$ reached a maximum value. On the other 
hand, the fluorescence intensity gradually decreased with concentrations of $\mathrm{HCl}$ from 2.0 to $3.0 \mathrm{~mL}$ (Fig. 2). Therefore, $2.0 \mathrm{~mL} 0.01 \mathrm{M} \mathrm{HCl}$ was adopted in the procedure.

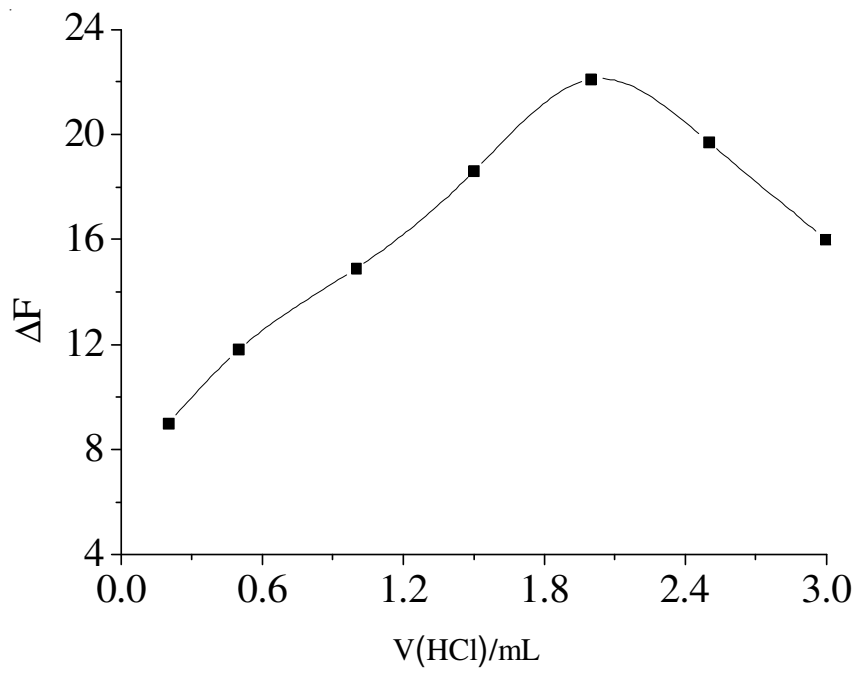

Fig. 2. Effect of the volume of $\mathrm{HCl}$ on $\Delta \mathrm{F}$ value of $\mathrm{HCHO}$

Effect of $\mathrm{KBrO}_{3}$ : The volume of $\mathrm{KBrO}_{3}$ also influences the change of fluorescence intensity for $\mathrm{HCHO}$ determination. $0.02 \mathrm{M} \mathrm{KBrO}_{3}$ was chosen as an oxidant in the system and its effect on $\Delta \mathrm{F}$ were investigated in the range of $0.2-2.0 \mathrm{~mL}$. It was showed the maximum value for $\Delta \mathrm{F}$ when $\mathrm{KBrO}_{3}$ volume was $1.2 \mathrm{~mL}$ (Fig. 3). Hence, $1.2 \mathrm{~mL} \mathrm{0.02} \mathrm{M} \mathrm{KBrO}_{3}$ was chosen for the following experiments.

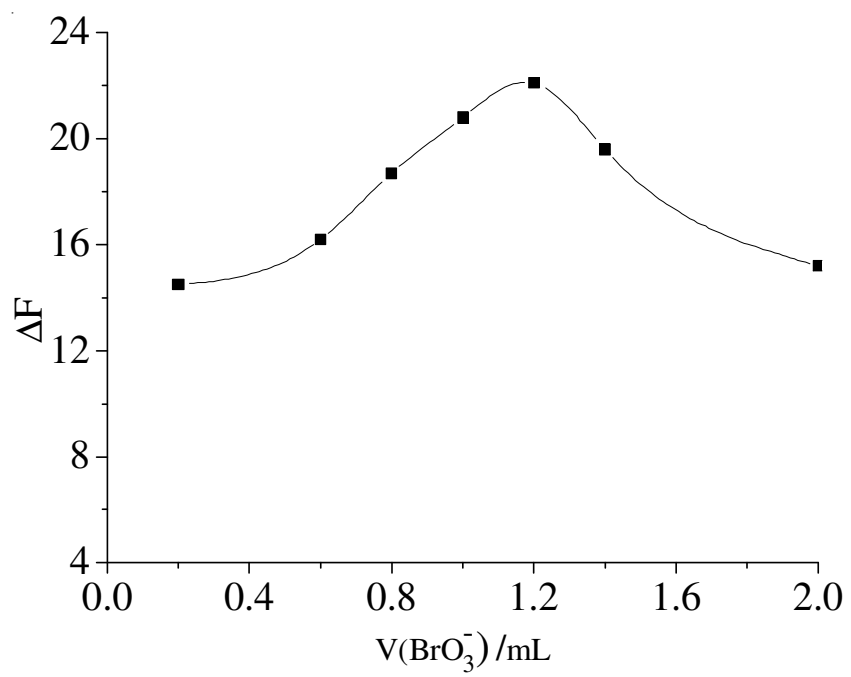

Fig. 3. Effect of the volume of $\mathrm{HBrO}_{3}$ on $\Delta \mathrm{F}$ value of $\mathrm{HCHO}$

Effects of temperature: The temperature is an important factor on the kinetic reaction. The effect of temperature was studied from 60 to $100^{\circ} \mathrm{C}$. The results (Fig. 4) showed that $\Delta \mathrm{F}$ had no obvious change below $80^{\circ} \mathrm{C}$. However, above $80^{\circ} \mathrm{C}$, $\Delta \mathrm{F}$ gradually increased with increasing temperature. In this work, the temperature was chosen for convenient operation at $100{ }^{\circ} \mathrm{C}$.

Effect of reaction time on fluorescence intensity: The influence of the reaction time on the change fluorescence intensity of system was examined. The results indicated that $\Delta \mathrm{F}$ gradually increased in the range of 4 to $10 \mathrm{~min}$ (Fig. 5). $\Delta \mathrm{F}$ obtained maximum value when the reaction time reached 10 min. On increasing time of reaction, $\Delta \mathrm{F}$ was decreasing. Thus, the best reaction time of 10 min was selected for the further experiment.

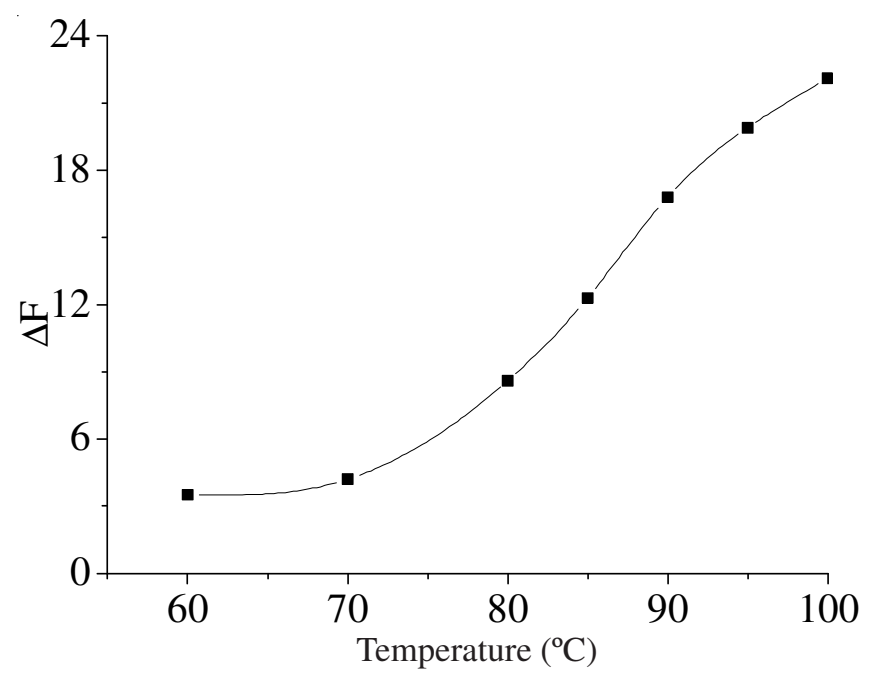

Fig. 4. Effect of temperature on $\Delta \mathrm{F}$ value of $\mathrm{HCHO}$

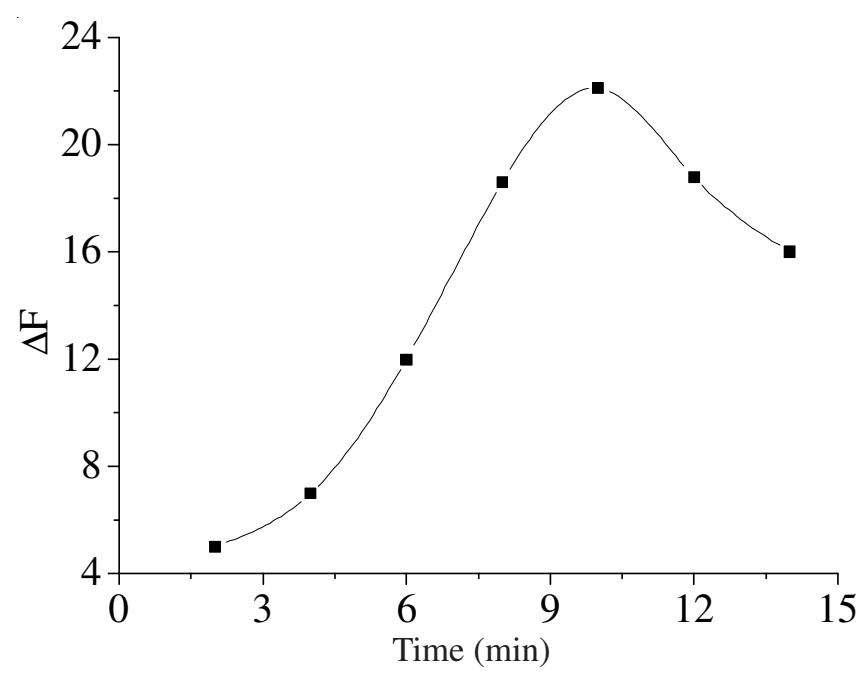

Fig. 5. Effect of reaction time on $\Delta \mathrm{F}$ value of $\mathrm{HCHO}$

Calibration curve: Under the optimum experimental conditions chosen above, a liner calibration curve was obtained in the range of $\mathrm{HCHO}$ concentration at $10.0-300 \mu \mathrm{g} / \mathrm{L}$. The correlation equation was $\Delta \mathrm{F}=3.3551+0.1215 \mathrm{c}(\mu \mathrm{g} / \mathrm{L}), \mathrm{R}=$ 0.9989. The detection limit is $5.8 \mu \mathrm{g} / \mathrm{L}$, which was calculated in the ratio of three times the standard deviation of $\Delta \mathrm{F}(\mathrm{n}=$ 12). The relative deviation $(\mathrm{n}=11)$ was $2.9 \%$ at $50 \mu \mathrm{g} / \mathrm{L}$ HCHO (Fig. 6).

Effects of interfering species: The influences of foreign species were examined by adding known amounts of interfering species. The tolerable defined as the concentration of foreign species causing less than $\pm 5 \%$ relative error in $50 \mu \mathrm{g} / \mathrm{L} \mathrm{HCHO}$ solution. The determination was not interfered by X-fold excesses of: $\mathrm{Na}^{+}, \mathrm{K}^{+}, \mathrm{Ca}^{2+}, \mathrm{Mg}^{2+}, \mathrm{SO}_{4}{ }^{2-}$ (1500), $\mathrm{NO}_{3}{ }^{-}$, toluene, methanol (1000), $\mathrm{NH}_{4}^{+}, \mathrm{Cu}^{2+}, \mathrm{Pb}^{2+}, \mathrm{Ba}^{2+}$, acetone, formic (500), $\mathrm{Ni}^{2+}$, acetic (300), $\mathrm{Mn}^{2+}(100)$, tartaric, acetaldehyde (50), phenol (25), $\mathrm{Fe}^{3+}(10)$. The results indicated that common foreign species slightly interference in water samples. 


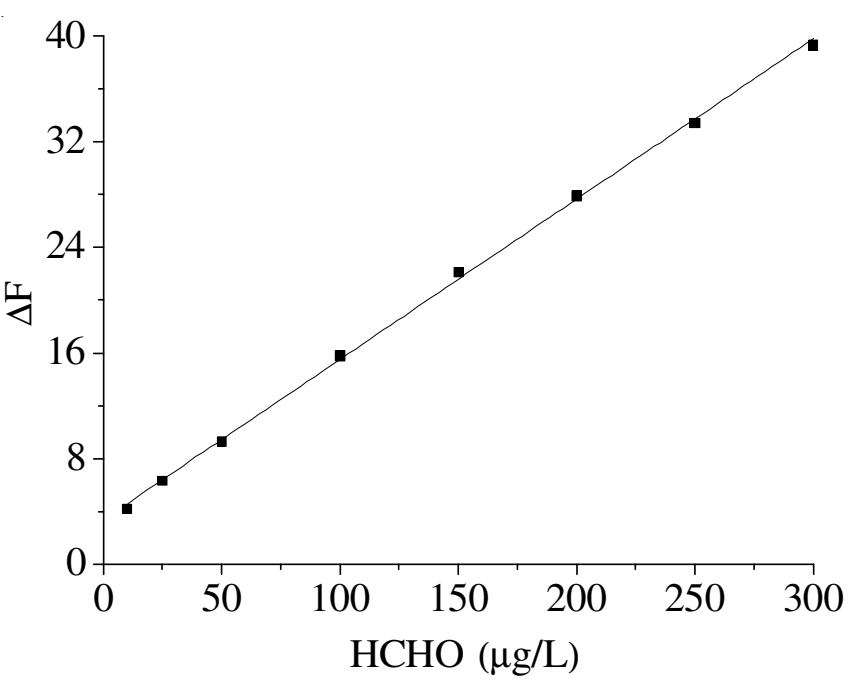

Fig. 6. Calibration curve

Samples analysis: To evaluate the analytical applicability of the method, the recommended procedure was applied to the determination of formaldehyde in river water and well water. The results determined by this new kinetic method were compared to the results obtained by the acetylacetone spectrophotometric standard procedure and the experiment results can be found in Table-1. The results show that the method is suitable for the analysis of real water samples.

\begin{tabular}{lcccc}
\multicolumn{5}{c}{ TABLE-1 } \\
RESULTS OF WATER SAMPLES \\
\hline Sample & $\begin{array}{c}\text { Added } \\
\left(\mu \mathrm{g} \mathrm{L}^{-1}\right)\end{array}$ & $\begin{array}{c}\text { Found } \\
\left(\mu \mathrm{g} \mathrm{L}^{-1}\right)^{*}\end{array}$ & $\begin{array}{c}\text { Recovery } \\
(\%)\end{array}$ & $\begin{array}{c}\text { Standard } \\
\text { method }\left(\mu \mathrm{g} \mathrm{L}^{-1}\right)\end{array}$ \\
\hline River & 0.00 & $13.6 \pm 0.04$ & - & $13.2 \pm 0.03$ \\
water & 25.00 & $39.0 \pm 0.09$ & 101.6 & $40.1 \pm 0.06$ \\
& 50.00 & $63.2 \pm 0.07$ & 99.2 & $60.1 \pm 0.08$ \\
& 75.00 & $87.3 \pm 0.03$ & 98.3 & $90.3 \pm 0.02$ \\
\hline Well & 0.00 & $8.7 \pm 0.05$ & - & $13.6 \pm 0.04$ \\
water & 25.00 & $33.1 \pm 0.09$ & 97.6 & $39.2 \pm 0.05$ \\
& 50.00 & $60.1 \pm 0.02$ & 102.8 & $63.1 \pm 0.04$ \\
& 75.00 & $85.4 \pm 0.06$ & 102.3 & $94.3 \pm 0.03$ \\
\hline *Mean \pm average deviation $(\mathrm{n}=5)$ & &
\end{tabular}

\section{Conclusion}

In present work, a novel technique for the determination of formaldehyde has been developed. The technique advantages are simple, sensitive and selective. When we applied this novel technique to detect the river water and well water, from the Table-1, we can safely conclude that we obtained satisfactory results. So the method can be determined for the detection of formaldehyde in real water samples.

\section{REFERENCES}

1. M.I. Khoder, A.A. Shakour and S.A. Farag, J. Environ. Monit., 2, 123 (2000).

2. H. Lovschall, M. Eiskjaer and D. Arenholt-Bindslev, Toxicol. in vitro, 16, 63 (2002)

3. K. Murai, M. Okano, H. Kuramitz, N. Hata, T. Kawakami and S. Taguchi, Anal. Sci., 24, 1455 (2008).

4. A.A. Mohamed, A.T. Mubarak, Z.M.H. Marestani and K.F. Fawy, Talanta, 74, 578 (2008).

5. A.A. Ensafi and E. Honarmand, Anal. Sci., 21, 545 (2005).

6. Z.W. Li, H.B. Ma, H.H. Lu and G.H. Tao, Talanta, 74, 788 (2008).

7. A. Afkhami and H. Bagheri, Microchim. Acta, 176, 217 (2012).

8. J. Koziel, M.Y. Jia, A. Khaled, J. Noah and J. Pawliszyn, Anal. Chim. Acta, 400, 153 (1999).

9. P. Martos and J. Pawliszyn, Anal. Chem., 70, 2311 (1998).

10. S. Kim and H.J. Kim, Holz Roh Werkst, 62, 101 (2004).

11. R.W. Gillett, H. Kreibich and G.P. Ayers, Environ. Sci. Technol., 34, 2051 (2000).

12. M.T. Oliva-Teles, P. Paiga, C.M. Delerue-Matos and M.C.M. AlvimFerraz, Anal. Chim. Acta, 467, 97 (2002).

13. J.F. Liu, J.F. Peng, Y.G. Chi and G.B. Jiang, Talanta, 65, 705 (2005).

14. E. Norkus, A. Vaskelis and R. Pauliukaite, Electroanalysis, 11, 447 (1999).

15. Z.Q. Zhang, H. Zhang and G.F. He, Talanta, 57, 317 (2002).

16. Y. Maeda, X. Hu and S. Itou, Analyst, 119, 2237 (1994).

17. K. Motyka, A. Onjia and P. Mikuška, Talanta, 71, 900 (2007).

18. T. Perez-Ruiz, C. Martinez-Lozano and V. Tomas, Anal. Bioanal. Chem., 375, 661 (2003).

19. J. Fan, Y.G. Tang and S.L. Feng, Int. J. Environ. Anal. Chem., 82, 361 (2002).

20. P. Sritharathikhun, M. Oshima and S. Motomizu, Talanta, 67, 1014 (2005).

21. Q. Li, P. Sritharathikhun and S. Motomizu, Anal. Sci., 23, 413 (2007).

22. J.K. Liu and L.H. Chen, Chin. Anal. Lab., 25, 78 (2006).

23. J. Fan, X.J. Tang and S.L. Feng, Chin. J. Anal. Chem., 30, 942 (2002). 